\title{
FORWARD PLANNING FOR SCOTTISH GARDENS IN THE FACE OF CLIMATE CHANGE
}

\author{
Chris Smart ${ }^{1} \&$ Alan Elliott ${ }^{2}$
}

\begin{abstract}
The impact of climate change and its effects on gardens has so far received limited academic attention. This paper offers a partial correction of this imbalance by investigating the potential impact of climate change on a selection of common Scottish garden plants. A climate envelope modelling approach was taken, whereby wild species distribution data were used to build climate 'envelopes' or descriptions of the native climates of selected species. The envelope models were projected onto future climate scenarios for Scotland, allowing observations to be made regarding the climatic suitability of Scotland, both currently and into the future, for each of the plants studied. The models and predictions for four species are described here along with strengths and limitations of the methodology. It is suggested that this approach, or variations of it, could become a useful tool in forward planning for gardens in assisting efforts to mitigate the effect of climate change.
\end{abstract}

\section{INTRODUCTION}

It is widely acknowledged that the climate of the United Kingdom will change over the course of the 21st century (Hulme et al., 2002). This is largely as a result of rising carbon dioxide levels worldwide (IPCC, 2013). There is a need for a better understanding of the likely impacts of climate change on UK gardens (Bisgrove \& Hadley, 2002). In partial answer to this need, the following study was undertaken to explore the impacts of climate change on Scottish gardens, specifically addressing the potential impacts on some common Scottish garden plants. This was as part of the author's completion of the BSc in Horticulture with Plantsmanship at Royal Botanic Garden Edinburgh (RBGE) in 2014.

Here four of the six species selected for the research are examined, each of which provides an insight into the range of results received and conclusions that may be drawn:

- Rhododendron luteum already grows well in many parts of Scotland and if the climate changes as expected the environment will be even more suitable for its cultivation.

- Clematis montana already grows well in many parts of Scotland, despite the fact that conditions in its native range suggest that the climate in Scotland would not be suitable. Therefore this envelope modelling tool does not enable conclusions to be drawn about its cultivation in the future.

1. Chris Smart is currently undertaking a practical horticulture work placement at the Royal Botanic Garden Edinburgh. Address: Beech House, Old Kirk Brae, Broughton, by Biggar ML12 6HF, UK.

Email: christopher.smart@live.co.uk

2. Alan Elliott is a PhD Researcher on the Flora of Nepal project at the Royal Botanic Garden Edinburgh.

Address: 20A, Inverleith Row, Edinburgh, EH3 5LR, UK. 
- Skimmia japonica grows well in some parts of Scotland but not others. The study shows that by 2070 the areas suitable for growing will be different from today and therefore those currently cultivating this species will have to either ameliorate the growing conditions or make different plant choices. However, gardens in other parts of the country such as Aberdeenshire and Shetland will be more likely to be able to successfully grow $S$. japonica than they can now.

- Meconopsis baileyi currently grows well in the cooler and wetter parts of Scotland. Climatic predictions are that the climate will get warmer and drier in the months when this species requires damp conditions. This will adversely affect growth of this species in all parts and therefore many gardens may not be able to grow it well.

\section{CLIMATE ENVELOPE MODELLING}

Investigations into climate change and its effect on plant distribution range across the academic spectrum. An overwhelming proportion of this research comes from the ecological sciences, where there is a general focus on predictive modelling as a means to envisage the spread or demise of species and habitats under different projected climate scenarios (Ibanez et al., 2006; Thomas et al., 2004). This type of modelling is called climate envelope or species distribution modelling (Thomas et al., 2004).

Climate envelope models use wild species distribution data to build descriptions of an organism's climatic requirements (Ibanez et al., 2006). Once these requirements are known it is possible to predict the climatic appropriateness of areas outside the species, current distribution or to predict what effect future climate changes may have.

Baseline plant distributions are required to understand the effects of climate change (Elith et al., 2006). It was believed that a climate envelope modelling approach could offer an insight into the climatic suitability of areas in Scotland in order to continue to grow some of our most common garden plants. This is relevant for horticulture because of the likely difficulty and subsequent potential inputs required to grow some species in the future.

\section{METHODOLOGY}

World climatic data (Bioclimatic or 'BioClim' variables) were downloaded from WorldClim (WorldClim, 2005). The data are broadly split into two data sets, one containing all the current world climatic conditions and the other containing the future world climatic predictions.

Using DIVA GIS software (Hijmans, 2010), all the climatic variables, both current and predicted, were cropped down from world-scale to that of just Scotland. This helped to improve the statistical significance and sensitivity of the model when it came to comparing species climate envelopes with the current and predicted Scottish climates.

To build species climate envelope models, distribution data in the form of latitude- 
longitude points were harvested from wild collected herbarium specimens and records held by botanic gardens for their wild collected living specimens. The vast majority of the data came from the Global Biodiversity Information Faculty (GBIF, 2014), records from the Chinese Virtual Herbarium (Chinese Virtual Herbarium, 2014), Tropicos (Tropicos, 2014) and the living specimen records at RBGE (RBGE, 2014).

In turn the latitude-longitude points for each species were projected onto the current climate world map in DIVA GIS which contained all the current climate data. As before, this was then cropped to an area just larger than the individual species distribution. In this way, the climate envelope models were created for each species. The climate envelopes were then tested using Maxent software (Phillips, 2006), which provided an insight into how accurately the model describes the species distribution; this also highlights which climatic variables affect the success or otherwise of the species.

The next task was to input the current Scottish environmental layer and test this against the native range to see if Scotland was climatically appropriate for the species. Within Scotland, Maxent was able to show areas that were considered appropriate for the species and those which were less so. In the areas that were shown to be inappropriate, Maxent highlighted the climatic variables which limited the success of the species, such as summer precipitation.

After establishing a species' capacity to survive in the current Scottish climate, the next step was to test the future environmental conditions for Scotland in order to begin to understand the effects that climate change may have on individual species.

\section{RESULTS AND DISCUSSION}

It was felt necessary that in order to comment on the projected success of a species within Scotland, there would need to be a predetermined definition of success based upon the Maxent output (Fig. 1). For ease of reference, this success was referred to as the Climatic Comfort Zone (CCZ) of a species. Species were considered to be within their CCZ if the Maxent output showed a 64 per cent prediction or above. Areas in Scotland shown to fall below this prediction percentage were considered to be less suitable for the species. The term CCZ is not to be confused with a general species comfort zone, a broader and more informal concept used in horticulture that takes into account other survivorship factors such as soil type, acidity, exposure, nutrient and water availability and drainage. CCZ is purely the climatic preferences of a species.

\section{RHODODENDRON LUTEUM}

The native range of Rhododendron luteum encompasses the temperate regions of Georgia, Armenia and Turkey (Fig. 1). 


\section{Prediction for Scotland - current}

The current Scottish climate is predicted to be highly suitable for $R$. luteum, more so than its native range (Fig. 2). This result suggests that $R$. luteum has the potential to be a highly invasive species in Scotland, as is the case with the hybrid $R$. ponticum. However, this is not observed in reality. This may be due to a lack of genetic competitiveness in $R$. luteum, unlike $R$. ponticum, which displays hybrid vigour, is non-deciduous and secretes allopathic compounds into the soil, suppressing other plant growth (NNSS, 2014).

The west of Scotland is an area where rhododendrons are highly successful, which can be largely attributed to the high precipitation and the milder growing conditions compared to the east and north (Cox \& Curtis-Machin, 2008). The prediction for $R$. luteum supports this observation; in the west, it is shown to be 100 per cent within its CCZ (Fig. 2).

Temperature seasonality and precipitation in the driest month were both shown to sit outwith the native range of $R$. luteum. This perhaps explains why most of Scotland is climatically more appropriate for this species; the temperature and precipitation are more constant throughout the year because of the oceanic climate, compared to its native range which is more continental in experiencing seasonal extremes (WorldClim, 2005). This climatic consistency would seem to favour growth of $R$. luteum in Scotland in the future.

\section{Prediction for Scotland - 2070}

By 2070 there is expected to be a slight change in the climate of the Lothians, Fife and Inverness compared to the current Scottish climate (Figs 2 and 3). However, these areas still appear to be within the CCZ of R. luteum. The west of Scotland, with its higher

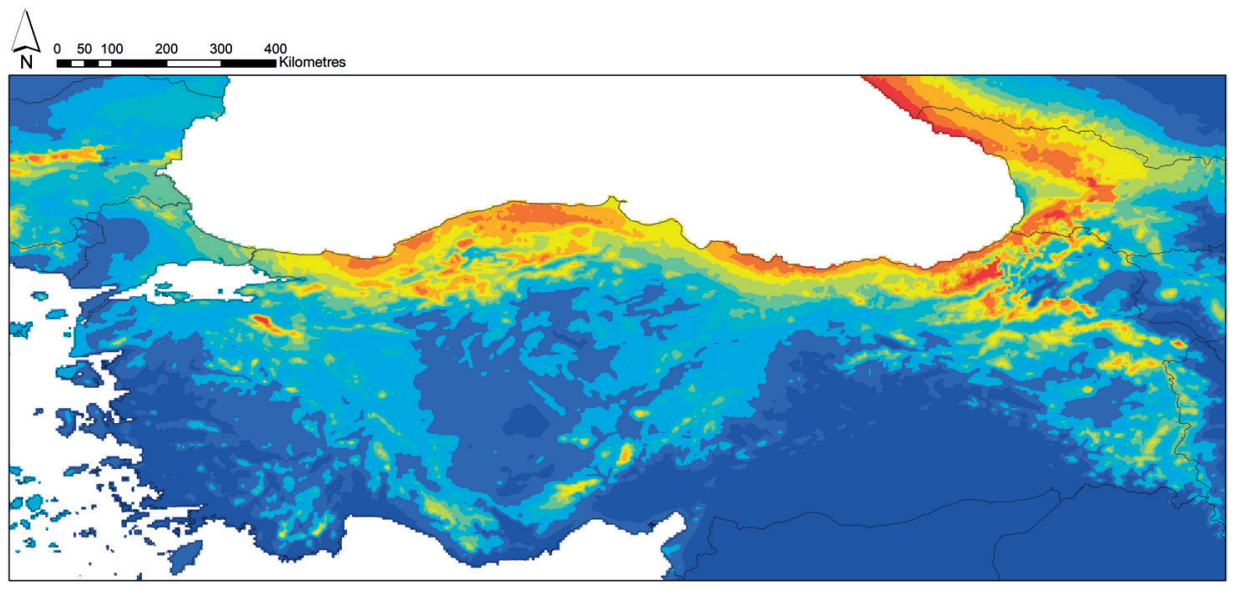

Fig. 1 R. luteum native range prediction. Warmer colours denote a stronger prediction. 


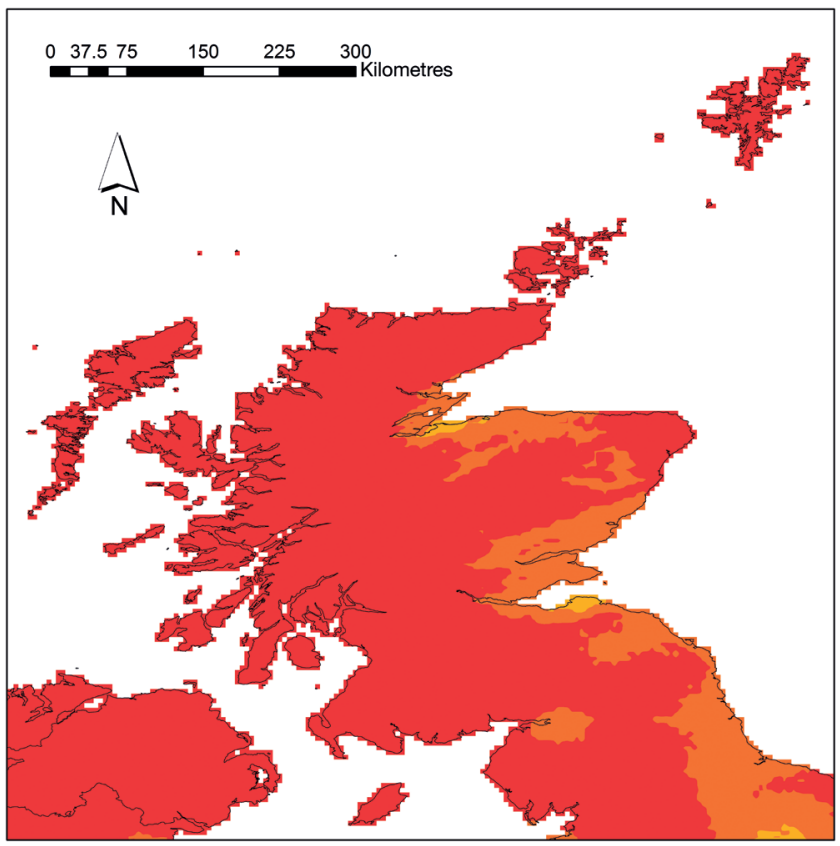

Legend

Climatic comfort zone (\%) <VALUE>

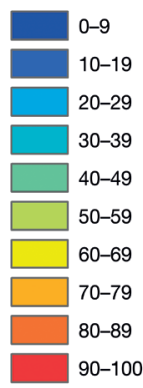

Fig. 2 The enlarged legend on the right classifies the colours on the map into prediction confidence percentages. Warmer colours on the map equate to a higher confidence of presence or climatic appropriateness. Colder colours are used to indicate areas where the species is less likely to be found, i.e. areas of less climatic suitability. Left hand image shows current predicted distribution (climatic appropriateness) of $R$. luteum within the current Scottish climate.

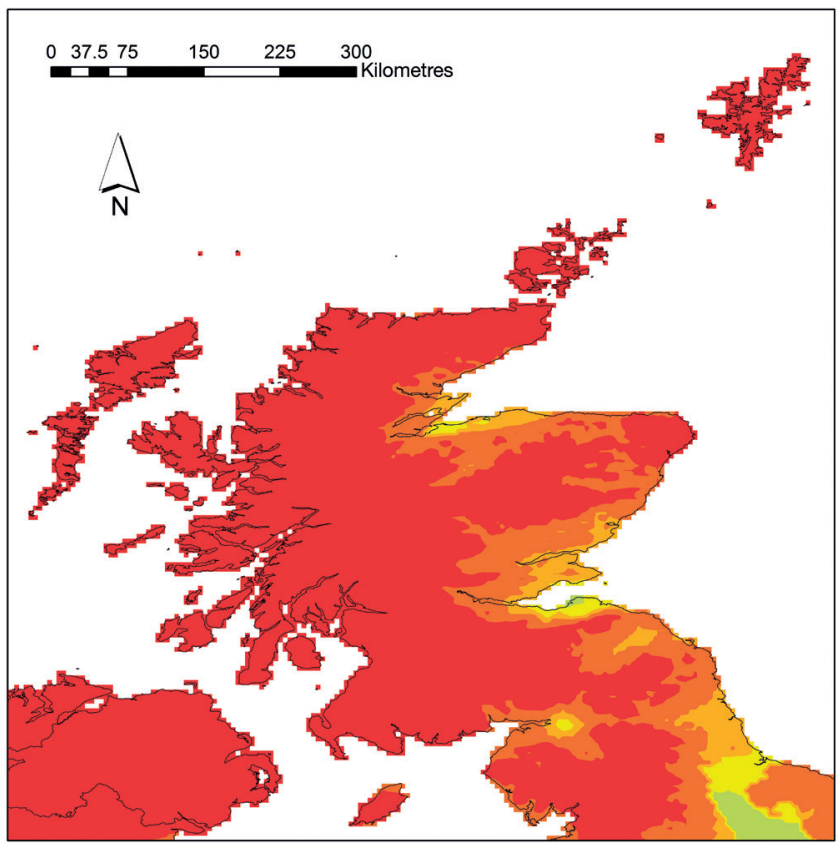

Fig. 3 R. luteum prediction for Scotland by 2070. 
rainfall, is still predicted to be the more climatically suitable area for growing this species. Again, both the temperature seasonality and precipitation in the driest month are outwith its native conditions. The prediction for R. luteum in Scotland suggests that conditions will remain more favourable here compared to its native range despite the predicted climatic shift.

\section{CLEMATIS MONTANA}

The distribution of Clematis montana (Fig. 4) exhibits a typical Sino-Himalayan distribution from Yunnan Province (China) in a north-westerly direction to Nepal and beyond, following the spread of the monsoon as it tracks the Himalayan mountain range.

\section{Prediction for Scotland - current}

The prediction for C. montana within Scotland (Fig. 5) indicates that the current Scottish climate is largely unfavourable. This is surprising given its widespread use and known reliability throughout Scottish gardens (Cox \& Curtis-Machin, 2008). This relatively poor prediction for Scotland could be attributed to the fact that the model only captures a species-realised niche and not its full potential range of climatic tolerances. Looking at its native range (Fig. 4) we see that despite the wide climatic tolerance of $C$. montana suggested by the model, it only grows between 1,000 $\mathrm{m}$ and 4,000 $\mathrm{m}$ in the Himalaya and mountains of south-west China; it is effectively trapped between two climatic extremes. To its north it is trapped by the arid alpine conditions of the Qinghai-Tibetan plateau; to its south, the hot, humid tropics. In this case it is easy to surmise that the model fails to fully capture the complete range of climate tolerance of $C$. montana. So the fact that we know it grows well in Scotland suggests that its potential fundamental niche is far greater than its realised niche in the wild.

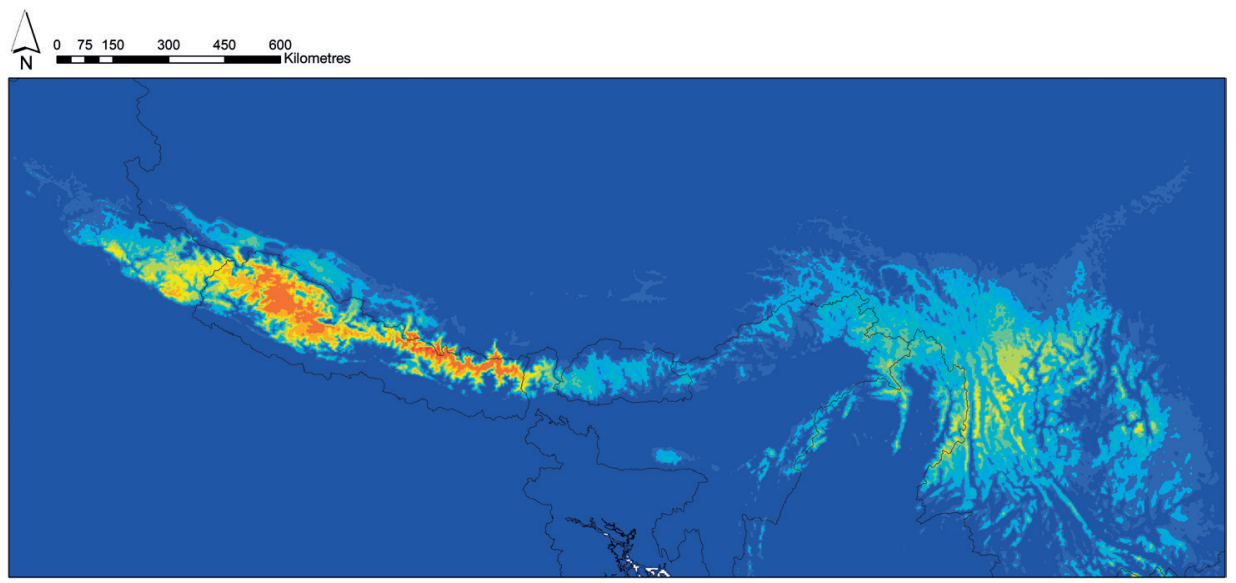

Fig. 4 C. montana native range prediction. 


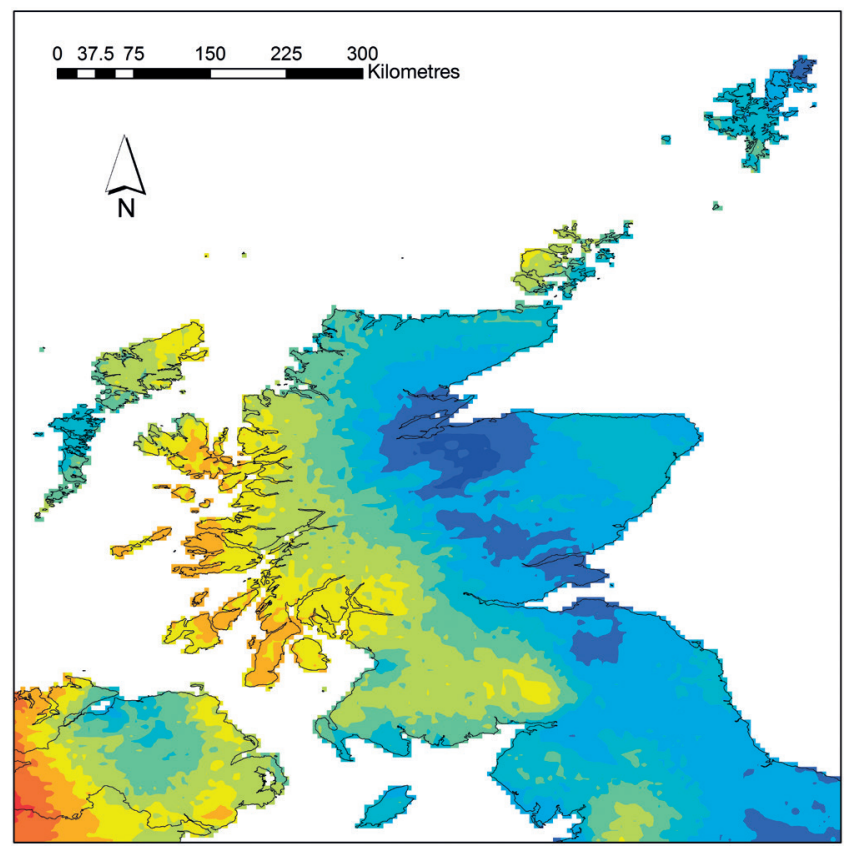

Fig. 5 Current predicted distribution (climatic appropriateness) of C. montana within the current Scottish climate.

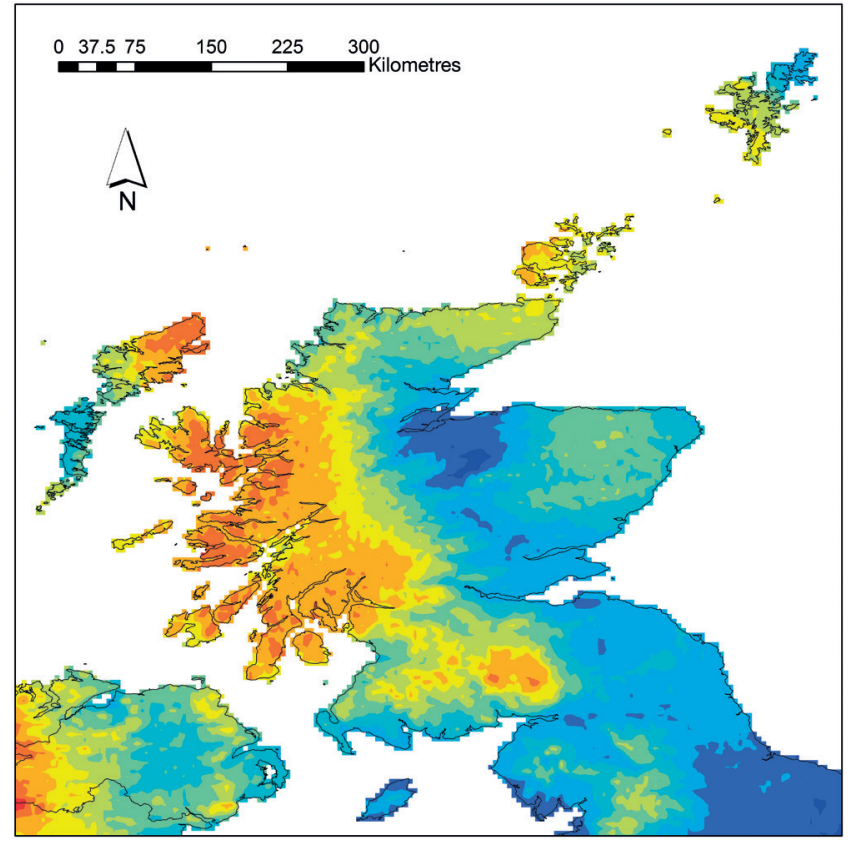

Fig. 6 C. montana prediction for Scotland by 2070. 


\section{Prediction for Scotland - 2070}

The prediction for 2070 also suffers from the same inconsistences between fundamental and realised niche. The results for 2070 cannot be relied upon to show an accurate prediction of $C$. montana success within the future Scottish climate (Fig. 6). That said, the prediction for 2070 is noticeably worse than the current prediction (Fig. 5). This may suggest that Scotland could become increasingly climatically unsuitable for C. montana; however, without a more accurate indication of its fundamental niche, it is impossible to say this with confidence.

It can be seen from the $C$. montana results that the realised niche captured in this type of modelling will not always be useful in predicting future climatic appropriateness.

\section{SKIMMIA JAPONICA}

Skimmia japonica displays an impressive distribution, both geographically and climatically speaking (Fig. 7). In its northernmost range, it is found to tolerate the cold conditions found in Hokkaido, Japan, while in the south of its range it can also tolerate the hot, sub-tropical conditions found in places such as Okinawa, an island in southern Japan.

\section{Prediction for Scotland - current}

There appears to be an east-west split in the current prediction for Scotland. The east of Scotland appears to sit within S. japonica's CCZ, whilst the central west Highlands appear to be less well suited (Fig. 8).

In the east, precipitation seasonality was flagged up as being different from $S$. japonica native distribution (Fig. 7). This is most likely because Scotland's oceanic climate experiences less variability than Japan's more continental climate, which features greater seasonal extremes (WorldClim, 2005). The west has generally less favourable conditions compared to the east, probably because of higher rainfall (WorldClim, 2005). This would be in agreement with the work of Cox \& Curtis-Machin (2008) who describe $S$. japonica as preferring moist yet well-drained conditions.

\section{Prediction for Scotland - 2070}

The 2070 results are interesting as they display the same trends observed in the predicted changes for Scotland but more exaggerated (Fig. 9). Comparing the two (Figs 8 \& 9), the main difference is that Aberdeenshire is predicted to become more appropriate or favourable for $S$. japonica, as is Shetland and the extreme western coastal areas. This climatic improvement could be attributed to both increases in winter temperatures and reductions in summer precipitation. For the rest of the country conditions are predicted to worsen slightly. The wettest parts of the west of Scotland are shown to be particularly climatically unsuitable. Therefore, as the climate changes some parts of Scotland will become more suitable for growing $S$. japonica and others will become less suitable. 


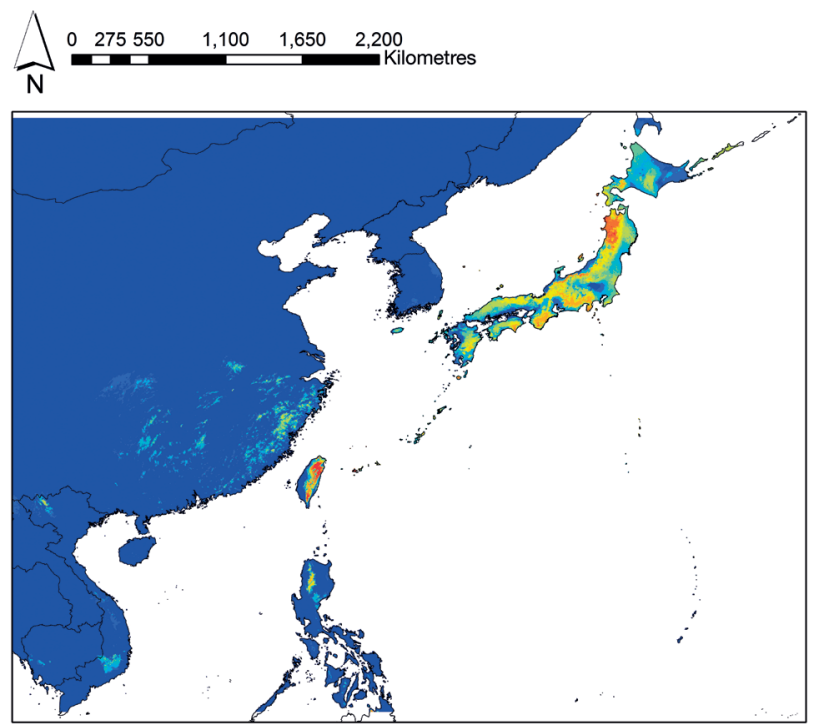

Fig. 7 S. japonica native range prediction.

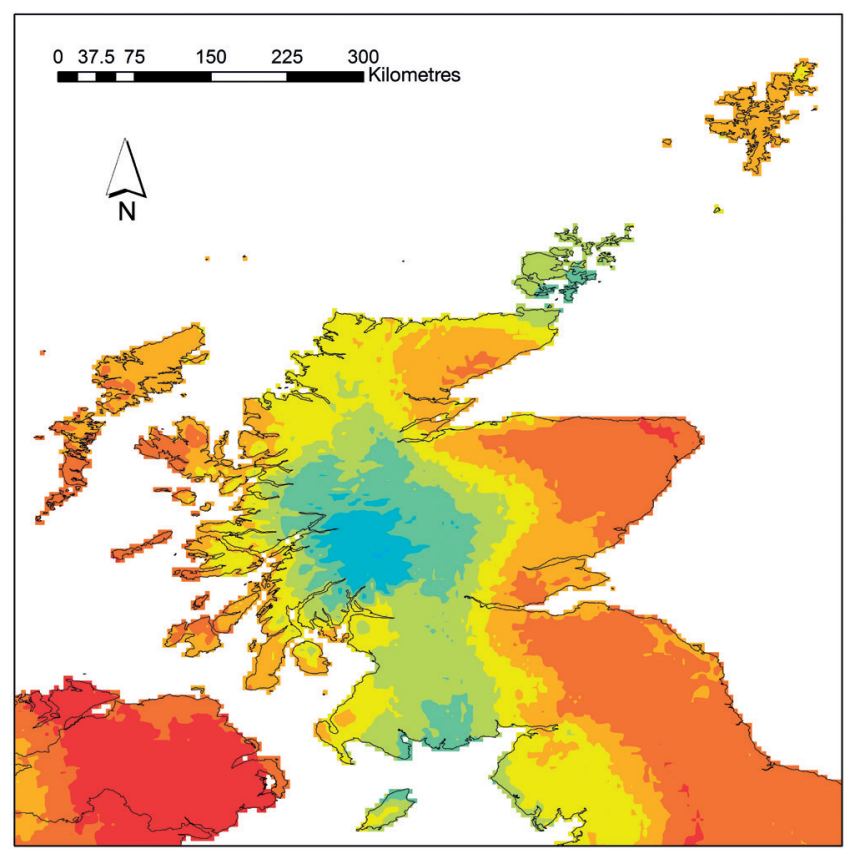

Fig. 8 Current predicted distribution (climatic appropriateness) of $S$. japonica within the current Scottish climate. 


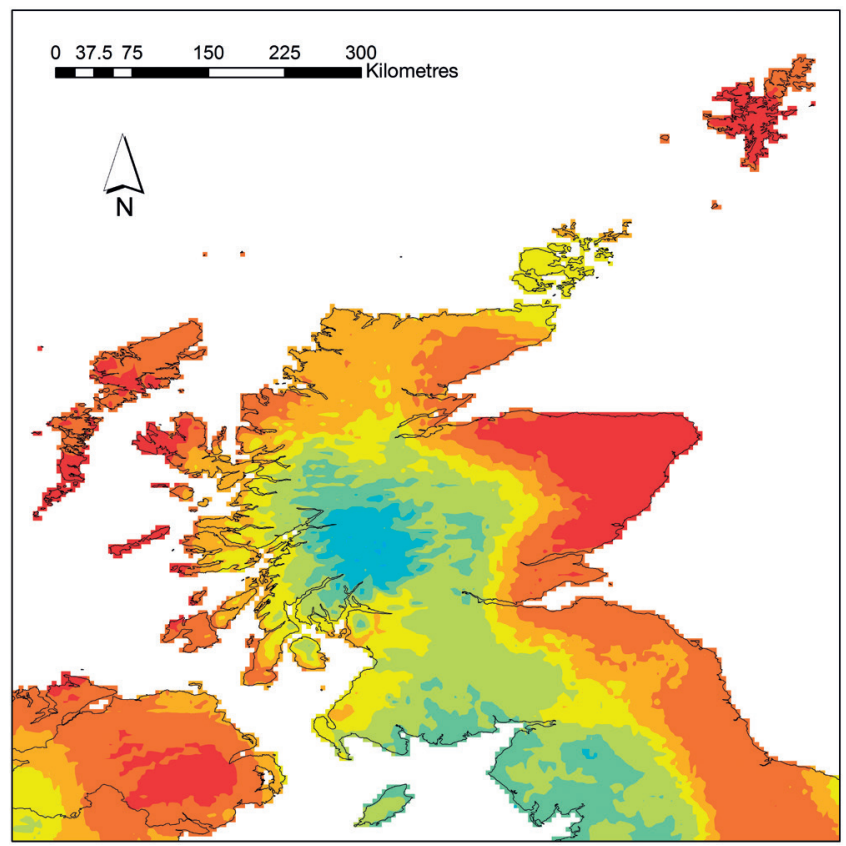

Fig. 9 S. japonica prediction for Scotland by 2070.

\section{MECONOPSIS BAILEYI}

Meconopsis baileyi is native to south-eastern Tibet. Its native climatic conditions can generally be characterised as being cool and damp. For this reason it has been particularly successful in growing in central Scotland where conditions are similar (Meconopsis Group, 2010).

\section{Prediction for Scotland - current}

The following analysis is provided courtesy of Alan Elliott (Elliott, 2014) using the same technique described above. The current prediction for M. baileyi in Scotland largely falls within what would be expected (Fig. 11). Most of Scotland is appropriate for growing $M$. baileyi with the exception of the wet, warmer western areas. Cold central and eastern areas are shown to be most appropriate; this is in line with the findings of Cox \& CurtisMachin, 2008.

\section{Prediction for Scotland - 2070}

By 2070, the suitable climatic conditions across Scotland for M. baileyi are predicted to reduce significantly (Fig. 12). Only the far north-east and parts of Shetland sit with its CCZ. The most important climatic change shown to contribute to this prediction is a lack of summer rainfall when the plant is actively growing. This is most likely to be the greatest 


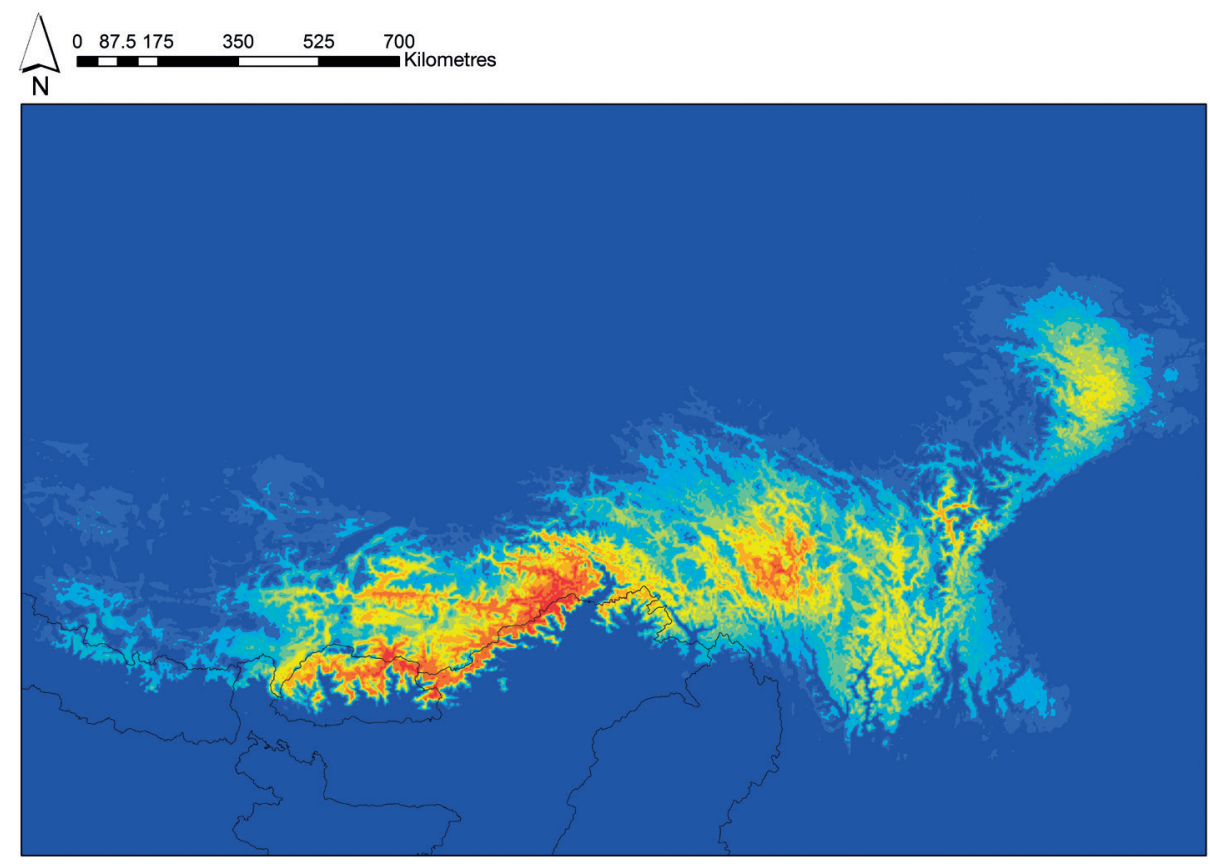

Fig. 10 Native range of M. baileyi.

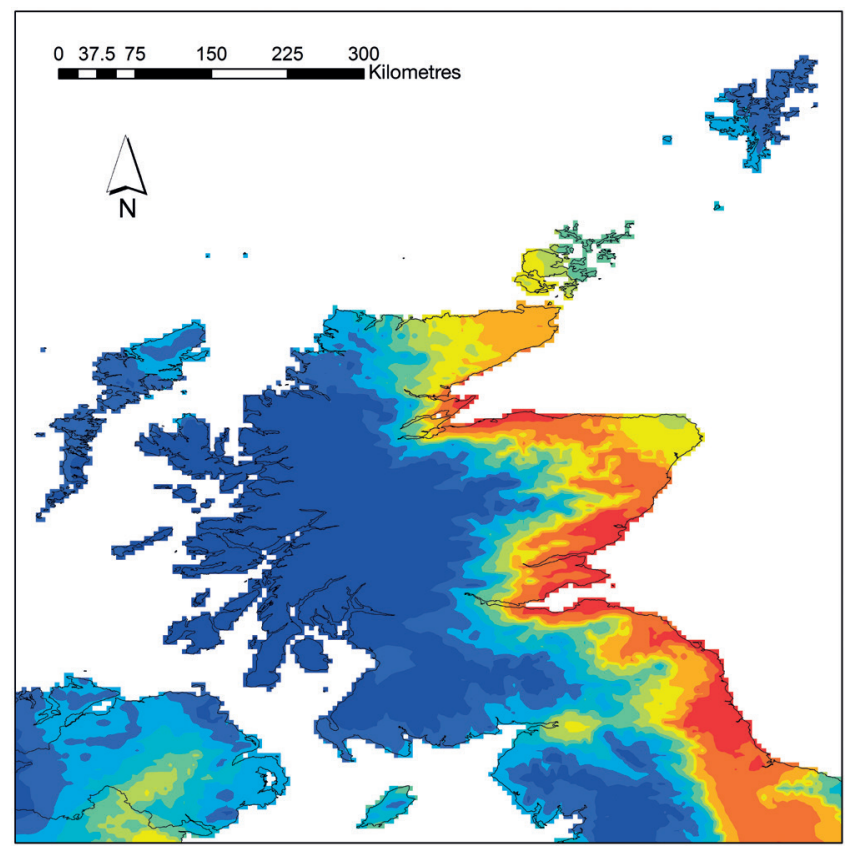

Fig. 11 Current predicted distribution (climatic appropriateness) of M. baileyi within the current Scottish climate. 


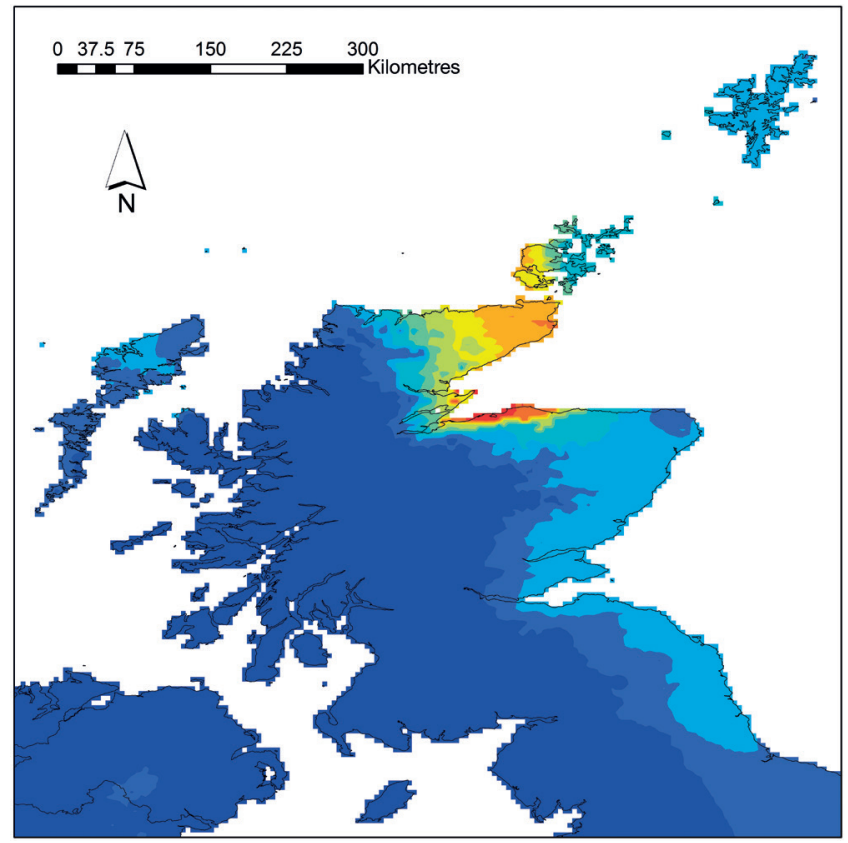

Fig. 12 M. baileyi prediction for Scotland by 2070.

environmental factor limiting the successful cultivation of $M$. baileyi. Increased average temperatures also play a role in reducing suitability. This corroborates anecdotal evidence about the loss of Meconopsis during hot dry summers in Fife, where additional watering has very little effect on the survival of the plants (Dr. James Cobb, 2012 pers. comm.).

In terms of cultivation $M$. baileyi looks to become increasingly difficult to grow. Irrigation will almost certainly be required as will more careful selection of cool microclimates within gardens.

\section{CONCLUSION}

The climate envelope approach by no means explains the full picture regarding the present or future success of common garden plants growing in Scotland. In particular, where a species envelope does not fully represent the fundamental niche, the model lacks basic accuracy, as was observed with Clematis montana.

The approach is valuable, however, in beginning to understand why some plants do particularly well in certain areas of Scotland, such as Rhododendron luteum which clearly prefers the conditions in the wetter parts of the west of Scotland. Conversely, Skimmia japonica prefers the drier eastern areas and the wetter western areas display poor climatic suitability for these species.

The envelope approach can offer a degree of insight into the climatic vulnerabilities of the plants we grow in Scotland. For example, Meconopsis baileyi would seem to be 
reliant upon the cool damp conditions currently present throughout most of Scotland. As these conditions change, it is expected that the climate will become less suitable to grow them. It is through understanding these vulnerabilities and modelling what is likely to happen in the future that gardens can forward plan, in terms of both species selection and infrastructure investment which may be needed to grow some plants well.

Species selection has always played a role in mitigating local climatic challenges that can limit the success of gardens (McColl, 2008), and so in that respect the age-old advice of 'the right plant for the right place' is a relevant concept here. On the other hand, investing in infrastructure such as irrigation systems that can mitigate some of the effects of climate change is perhaps a less familiar consideration for some gardeners. The east of Scotland is predicted to experience increasing seasonal dryness (WorldClim, 2005), which may begin to affect the climatic suitability of some of the alpine and sub-alpine groups of plants, as was shown to be the case with Rhododendron luteum and Meconopsis baileyi.

It would seem plausible that species most susceptible to this change would, like Meconopsis, be herbaceous. It may also be worthwhile to test other common herbaceous species such as primulas, lupins, astilbes and saxifrages, all of which currently thrive in our oceanic climate, characterised by even precipitation throughout the year and low temperature seasonality (Cox \& Curtis-Machin, 2008). If we wish to continue to grow these plants, it may become necessary to rely less on the weather to maintain plants and perhaps more on artificial infrastructure such as irrigation and soil water retention strategies such as mulches and water-smart compost.

Modelling has provided an increased understanding, limitations notwithstanding, of which areas in Scotland are likely to continue to be good for certain plants and which areas may become increasingly unsuitable in the future. The implications of these findings are not absolute, because climatic suitability is but one parameter amongst a range of other factors that allow a plant to survive. These other factors include soil type and acidity, but perhaps more uniquely to horticulture are the concepts of aspect and microclimate, which can prove fundamental in dictating success with a plant (McColl, 2008; RHS, 2013). That said, climate will always be one of the strongest limitations to any garden and mitigating the effect of climate change, whilst possible, can prove financially and practically difficult. Knowing which parts of Scotland are going to change and how those changes will affect groups of plants should be an integral aspect of forward planning for Scottish gardens.

\section{REFERENCES}

BISGROVE, R. \& HADLEY, P. (2002). Gardening in the Global Greenhouse: the Impacts of Climate Change on Gardens in the UK. UKCIP, Oxford.

CHINESE VIRTUAL HERBARIUM (2014). Available online: www.cvh.org.cn (accessed April 2014). 
COX, K.N. \& CURTIS-MACHIN, R. (2008). Garden Plants for Scotland, 1st edn. Frances Lincoln, London.

ELITH, J., GRAHAM, C., ANDERSON, R. \& DUDÍK, M. (2006). Novel methods improve prediction of species' distributions from occurrence data. Ecography 29(2): 129-151.

ELLIOTT, A. (2014). Presentation to the Meconopsis group.

GBIF (2014). Global Biodiversity Information Facility. Available online: www.gbif.org (accessed April 2014).

HIJMANS, R., 2010. DIVA-GIS. Available online: www.diva-gis.org (accessed April 2014).

HULME, M., JENKINS, G.J., LU, X., TURNPENNY, J.R., MITCHELL, T.D., JONES, R.G., LOWE, J., MURPHY, J.M., HASSELL, D., BOORMAN, P., MCDONALD, R. \& HILL, S. (2002). Climate change scenarios for the United Kingdom: the UKCIP02 Scientific Report. Tyndall Centre for Climate Change Research, School of Environmental Sciences, University of East Anglia, Norwich.

IBANEZ, I., CLARK, J.S., DIETZE, M.C., FEELEY, K., HERSH, M., LADEAU, S., MCBRIDE, A., WELCH, N.E. \& WOLOSIN, M.S. (2006). Predicting biodiversity change: outside the climate envelope, beyond the species-area curve. Ecology 87(8): 1896-1906.

IPCC (2013). Summary for Policymakers. In: Climate Change 2013: The Physical Science Basis. Contribution of. Cambridge University Press, Cambridge.

MCCOLL, J. (2008). Foreword. In: COX, K.N. \& CURTIS-MACHIN, C. (eds). Garden Plants for Scotland. Frances Lincoln, London, p. 7.

MECONOPSIS GROUP (2010). The Meconopsis Group. Available online: www.meconopsis. org/species/baileyi/baileyi.html (accessed April 2014).

NNSS (2014). Rhododendron, Rhododendron ponticum factsheet. Available online: www. nonnativespecies.org/factsheet/downloadFactsheet.cfm?speciesId=3004 (accessed April 2014).

PHILLIPS, S. (2006). Maxent software for species habitat modelling. Available online: www. cs.princeton.edu/ schapire/maxent/ (accessed July 2015).

RBGE (2014). RBGE Herbarium Catalogue. Available online: http://elmer.rbge.org.uk/bgbase/ vherb/bgbasevherb.php (accessed April 2014).

RHS (2013). What Plant Where Encyclopedia. 1st edn. Dorling Kindersley, London.

THOMAS, C.D., CAMERON, A., GREEN, R.E., BAKKENES, M., BEAUMONT, L.J., COLLINGHAM, Y.C., ERASMUS, B.F.N., FERREIRA DE SIQUEIRA, M., GRAINGER, A., HANNAH, L., HUGHES, L., HUNTLEY, B., VAN JAARSVELD, A.S., MIDGLEY, G.F., MILES, L., ORTEGA-HUERTA, M.A., PETERSON, A.T., PHILLIPS O.L. \& WILLIAMS, S.E. (2004). Extinction risk from climate change. Nature 427: 145-148.

TROPICOS (2014). Available online: www.tropicos.org (accessed April 2014).

WORLDCLIM (2005). WorldClim global climate data. Available online: www.worldclim.org (accessed November 2013). 